\title{
CaMKII Inhibition is a Novel Therapeutic Strategy to Prevent Diabetic Cardiomyopathy
}

\author{
Christopher R. Veitch, Amelia S. Power and Jeffrey R. Erickson* \\ Department of Physiology and HeartOtago, University of Otago, Dunedin, New Zealand
}

\section{OPEN ACCESS}

Edited by:

Andrew J. Murray,

University of Cambridge,

United Kingdom

Reviewed by:

Steffen Pabel,

University of Regensburg, Germany

Péter Ferdinandy,

Semmelweis University, Hungary

*Correspondence:

Jeffrey R. Erickson

jeff.erickson@otago.ac.nz

Specialty section:

This article was submitted to Translational Pharmacology,

a section of the journal

Frontiers in Pharmacology

Received: 14 April 2021 Accepted: 14 July 2021

Published: 26 July 2021

Citation:

Veitch CR, Power AS and Erickson JR

(2021) CaMKIl Inhibition is a Novel

Therapeutic Strategy to Prevent

Diabetic Cardiomyopathy.

Front. Pharmacol. 12:695401.

doi: 10.3389/fphar.2021.695401
Increasing prevalence of diabetes mellitus worldwide has pushed the complex disease state to the foreground of biomedical research, especially concerning its multifaceted impacts on the cardiovascular system. Current therapies for diabetic cardiomyopathy have had a positive impact, but with diabetic patients still suffering from a significantly greater burden of cardiac pathology compared to the general population, the need for novel therapeutic approaches is great. A new therapeutic target, calcium/calmodulin-dependent kinase II (CaMKII), has emerged as a potential treatment option for preventing cardiac dysfunction in the setting of diabetes. Within the last 10 years, new evidence has emerged describing the pathophysiological consequences of CaMKII activation in the diabetic heart, the mechanisms that underlie persistent CaMKII activation, and the protective effects of CaMKII inhibition to prevent diabetic cardiomyopathy. This review will examine recent evidence tying cardiac dysfunction in diabetes to CaMKIl activation. It will then discuss the current understanding of the mechanisms by which CaMKII activity is enhanced during diabetes. Finally, it will examine the benefits of CaMKII inhibition to treat diabetic cardiomyopathy, including contractile dysfunction, heart failure with preserved ejection fraction, and arrhythmogenesis. We intend this review to serve as a critical examination of CaMKIl inhibition as a therapeutic strategy, including potential drawbacks of this approach.

Keywords: CaMKII, diabetes, O-GIcNAc, oxidation, nitrosylation, arrhythmia, cardiomyopathy

\section{INTRODUCTION}

Diabetes Mellitus (DM) is a global health problem of rapidly increasing importance affecting millions worldwide, with this number only set to increase (Ogurtsova et al., 2017). DM is culpable for an increased susceptibility to cardiovascular disease (CVD) mortality among afflicted patients, this link being established by the landmark Framingham study (Garcia et al., 1974), which has been further corroborated by multitudes of other independent researchers (Kessler, 1971; Kannel and McGee, 1979; Gu et al., 1998). In order to lessen the significant impact of CVD-related morbidity within the diabetic population, novel molecular targets need to be investigated for their therapeutic benefit, and one such emerging target is the multifunctional enzyme Calcium/calmodulin $\left(\mathrm{Ca}^{2+} / \mathrm{CaM}\right)$ dependent protein kinase II (CaMKII).

Calcium/calmodulin $\left(\mathrm{Ca}^{2+} / \mathrm{CaM}\right)$ dependent protein kinase II (CaMKII) is an important nodal signalling molecule in the cardiovascular system, playing a number of roles in $\mathrm{Ca}^{2+}$ signal transduction pathways (for review, Hudmon and Schulman (2002) that are essential to normal cardiac function such as excitation contraction coupling (ECC). CaMKII activation contributes to tuning of the sinoatrial node (SAN) function (Vinogradova et al., 2000) as well as underlying the 


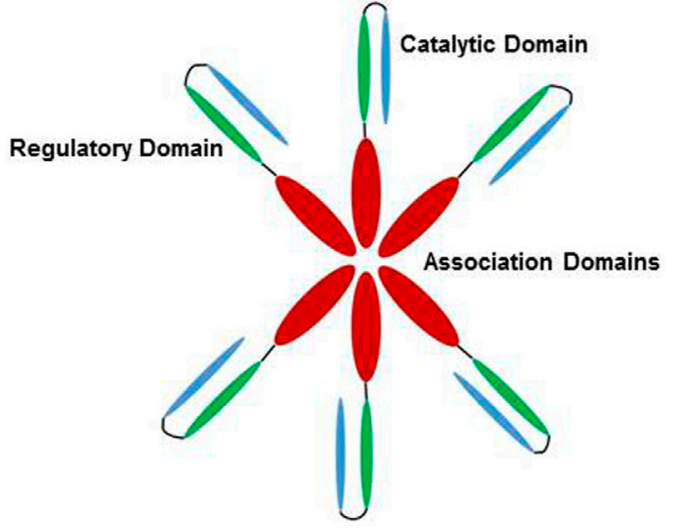

CaMKII - basal/autoinhibited state

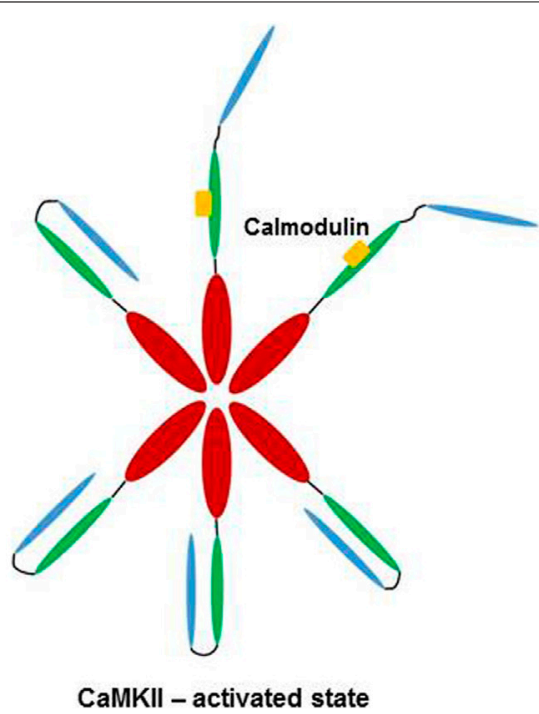

CaMKII - activated state

FIGURE 1 | Activation of CaMKII by $\mathrm{Ca}^{2+} / \mathrm{CaM}$. In low $\mathrm{Ca}^{2+} / \mathrm{CaM}$ concentrations, the catalytic domain (blue) is autoinhibited by the regulatory domain (green). Subunits of the dodecamer are held together by the association domains (red). High $\mathrm{Ca}^{2+} / \mathrm{CaM}$ concentrations (yellow) lead to binding of Ca ${ }^{2+} / \mathrm{CaM}$ to the regulatory domain, releasing the catalytic domain of CaMKII and allowing for enzymatic activity. Veitch 2021, original work.

chronotropic response of the SAN to $\beta$-adrenergic stimulation (Wu et al., 2009). Chronic activation of cardiac CaMKII is associated with increased myocyte apoptosis (Zhu et al., 2003), fibrosis (Luo et al., 2013), hypertrophy (Ljubojevic-Holzer et al., 2020) and heart failure (Hoch et al., 1999), all of which are also observed in animal models and clinical presentation of diabetes [for review, Murtaza et al. (2019)]. CaMKII is also central in many arrhythmogenic processes (Erickson and Anderson, 2008), along with the heightened arrhythmia seen in diabetic cardiomyopathy (DCM) (Daniels et al., 2015). This review aims to compare emerging evidence as to the roles of different novel CaMKII activation pathways in the diabetic heart, and the pathological consequences of these modifications.

\section{CALCIUM/CALMODULIN (CA2+/CAM) DEPENDENT PROTEIN KINASE II ACTIVATION IN DIABETES}

CaMKII is a dodecameric holoenzyme, consisting of three distinct domains. The association domain allows for assembly of the various subunits into a dodecamer, the catalytic domain interacts with substrates and performs the kinase activity of the enzyme, and the regulatory domain interacts with the catalytic domain to sterically occlude substrate binding, resulting in autoinhibition of CaMKII at basal conditions (Rosenberg et al., 2005; Erickson, 2014). The regulatory domain also contains a calmodulin-binding region, and association with $\mathrm{Ca}^{2+} / \mathrm{CaM}$ disrupts the interaction between the regulatory and catalytic domains, activating the kinase and allowing CaMKII to phosphorylate targets. High or persistently elevated $\mathrm{Ca}^{2+} / \mathrm{CaM}$ concentrations result in autophosphorylation of the enzyme, allowing for subsequent $\mathrm{Ca}^{2+} / \mathrm{CaM}$ independent activity (Lai et al., 1986; Rosenberg et al., 2005). Activation of CaMKII is shown schematically in Figure 1.

In addition to autophosphorylation, CaMKII can be chronically activated by a variety of post-translational modifications (PTMs) (Erickson, 2014), many of which take on increased prominence in the context of the diabetic milieu (Daniels et al., 2015). Indeed, elevated levels of blood glucose, increased calcium flux, enhanced production of reactive oxygen species (ROS) and aberrant nitric oxide signalling are well characterised in the setting of diabetes (Varga et al., 2015). Importantly, all of these cellular stresses are known to activate CaMKII. However, the contributions of each of these PTMs to the activation of CaMKII in the setting of DM has not been fully delineated. This section will aim to highlight the different modifications occurring to the enzyme in DM, along with summarising conflicting viewpoints on the contributions of various PTMs. The various PTMs occurring to the regulatory domain of CaMKII are highlighted in Figure 2.

\section{Oxidation in Diabetes}

Oxidation of methionine residues 281/282 leads to $\mathrm{Ca}^{2+} / \mathrm{CaM}$ independent autonomous activation of CaMKII akin to autophosphorylation (Erickson et al., 2008). Levels of prooxidants and oxidised proteins are heightened in both the plasma and pancreas of human and animal models, from the various effects of hyperglycemia on inflammatory processes and alteration of anti-oxidant enzymes [for review, Rehman and Akash (2017)].Mitochondrial ROS production in the myocardium is known to be increased in both T1 (Pham et al., 2014) and T2DM (Boudina et al., 2007). Oxidised CaMKII (ox-CaMKII) has been implicated as an arrhythmogenic substrate in diabetes and may play an integral role in the greater mortality rates seen in diabetic patients and 


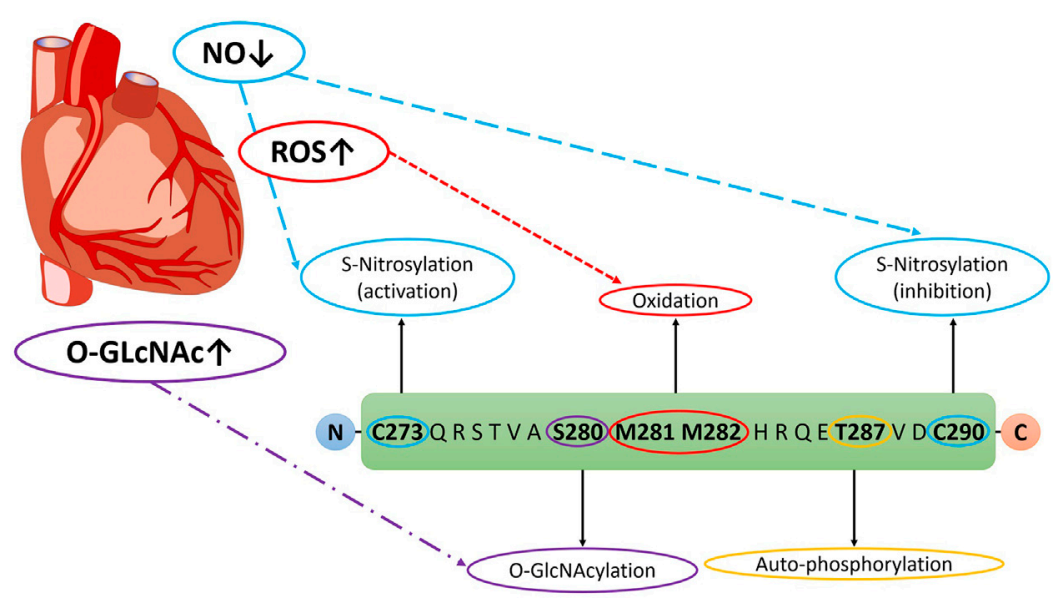

FIGURE 2 | Post-translational modifications on CaMKII Regulatory Domain in DM. Veitch 2021, original work.

animal models (Luo et al., 2013; Mesubi et al., 2020). For example, ox-CaMKII increases the risk of mortality following a myocardial infarction in diabetic and non-diabetic mouse models (Erickson et al., 2008; Luo et al., 2013).

Diabetes is strongly associated with arrhythmia in human patients (Movahed et al., 2005) and ox-CaMKII may underlie this increased risk of arrhythmogenesis. Ox-CaMKII augments the late $\mathrm{Na}^{+}$current $\left(I_{\mathrm{Na}}\right)$ in isolated ventricular cardiomyocytes from WT mice and rabbits, leading to accumulation of cytosolic $\mathrm{Na}^{+}$ and increased $\mathrm{Ca}^{2+}$ entry via the sodium/calcium exchanger (NCX) (Wagner et al., 2011). This ultimately leads to $\mathrm{Ca}^{2+}$ overload, contractile dysfunction and hypercontracture, along with $\mathrm{Ca}^{2+}$ sparks and SR Ca ${ }^{2+}$ leak (Wagner et al., 2011). Blocking CaMKII in mouse ventricular myocytes with inhibitor KN-93 was unable to affect $\mathrm{H}_{2} \mathrm{O}_{2}$-induced increases in $\mathrm{Ca}^{2+}$ sparks, suggesting that oxidative stress resulted in autonomous activation of the enzyme, preventing the inhibitory action of KN-93, which can only block CaMKII activity if the enzyme has not been autonomously activated (Buard et al., 2010). Investigators have also suggested that CaMKII acts as a sensor for ROS, translating heightened oxidative stress into enhanced susceptibility to atrial fibrillation (AF) showing a resistance to AF induction in a mouse model missing oxidation sites on CaMKII $\delta$ (MM-VV) (Purohit et al., 2013). This group further identified significantly increased levels of ox-CaMKII in human AF patients, implicating ox-CaMKII in the pathogenesis of human AF (Purohit et al., 2013). Interestingly, human AF patients treated with ACE inhibitors or angiotensin receptor blockers did not show similarly elevated levels of ox-CaMKII as untreated patients (Purohit et al., 2013) consistent with prior observations connecting elevated angiotensin II and aldosterone to the generation of excess ox-CaMKII (Erickson et al., 2008; He et al., 2011). Murine models of Duchenne muscular dystrophy show significantly increased ox-CaMKII, which may be linked to early stages of dystrophic cardiomyopathy (Wang et al., 2018). Ox-CaMKII may also mediate the cardiotoxic/arrhythmic sideeffects of cardiac glycosides, with excess ROS generated by NOX2 oxidizing CaMKII acting on RyR2 to generate proarrhythmic
$\mathrm{Ca}^{2+}$ waves (Ho et al., 2014). Taken together, these studies suggest that therapies focused on preventing CaMKII oxidation could alleviate arrhythmogenesis in the diabetic heart. The interactions of ox-CaMKII with various molecular targets associated with arrhythmia in both diabetes and other disease models suggest a pivotal role of ox-CaMKII in the generation of arrhythmogenic events. As oxidative stress is known to be heightened in diabetes, this modification could provide a useful target to alleviate the increased risk of arrythmia in diabetic patients.

\section{O-GlcNAcylation in Diabetes}

O-GlcNAcylation is the PTM of a protein via addition of an O-linked $\beta$-N-acetylglucosamine (O-GlcNAc) residue onto proteins at serine or threonine residues. This modification is influenced by two enzymes; O-GlcNAc transferase (OGT) and O-GlcNAcase (OGA), which catalyze the addition and removal of $\mathrm{O}-\mathrm{GlcNAc}$ residues respectively. This modification has garnered increasing interest due to its involvement in pathological processes associated with DM, in which the balance of signaling between phosphorylation and O-GlcNAcylation is disrupted (Butkinaree et al., 2010). The substrate for O-GlcNAcylation, UDP-GlcNAc, is regulated through the hexosamine biosynthesis pathway (HBP), which shuttles intracellular glucose through the pathway to produce UDPGlcNAc for O-GlcNAcylation. In DM, glucose may be favoured to be metabolised through alternative pathways such as the HBP due to impairments in insulin signaling, leading to elevated concentrations of UDP-GlcNAc in diabetic mice (Clark et al., 2003). This increase in UDP-GlcNAc production causes an elevation in O-GlcNAc modifications on proteins, as has been observed in left ventricular and right atrial appendage samples from diabetic patients (Prakoso et al., 2021).

CaMKII can be O-GlcNAcylated at the S279 residue, causing autonomous activation in a similar manner to autophosphorylation and oxidation (Erickson et al., 2013). O-GlcNAcylated CaMKII is significantly increased in the hearts of diabetic rats and human diabetic patients (Erickson et al., 2013; Daniels et al., 2018). This increase in O-GlcNacylated 
CaMKII underpins a number of mechanisms that promote cardiac arrhythmia. Hyperglycemia-induced activation of CaMKII occurs via O-GlcNAc modification and induces spontaneous $\mathrm{Ca}^{2+}$ leak in isolated rat cardiomyocytes, premature ventricular contractions in ex vivo rat hearts, and increased arrhythmia susceptibility in diabetic rats during a caffeine stress test (Erickson et al., 2013). O-GlcNAc-CaMKII also modulates $\mathrm{K}^{+}$channels, affecting both transient outward and rectifier $\mathrm{K}^{+}$current in rodent myocytes, leading to increased arrhythmia susceptibility (Hegyi et al., 2019).

Clark, McDonough (Clark et al., 2003) showed that increased O-GlcNAcylation in cardiomyocytes results in abnormalities in $\mathrm{Ca}^{2+}$ flux, which can be remedied by inhibiting O-GlcNAcylation. Interestingly, this amelioration of $\mathrm{Ca}^{2+}$ flux occurs despite ongoing hyperglycaemia, suggesting that O-GlcNAcylation and not hyperglycaemia is causing these overt disruptions in $\mathrm{Ca}^{2+}$ transport (Clark et al., 2003). In a Zucker diabetic fatty (ZDF) rat model of type II diabetes, Fülöp et al. (2007) found these animals exhibited impaired cardiac relaxation, depressed peak $\mathrm{Ca}^{2+}$ transient levels and slower rates of $\mathrm{Ca}^{2+}$ decay, which were associated with increased levels of O-GlcNAcylation. In addition to altering $\mathrm{Ca}^{2+}$ flux, excessive O-GlcNAcylation can produce contractile dysfunction in diabetic cardiomyopathy, via affecting $\mathrm{Ca}^{2+}$ sensitivity of the myofilaments (Ramirez-Correa et al., 2015). Although these studies do not directly implicate O-GlcNAc-CaMKII in diabetes, the studied abnormalities are well characterised to be directly affected by CaMKII $\left(\mathrm{Ca}^{2+}\right.$ fluxand cardiac contraction) so it is not far-fetched to suggest that CaMKII may be playing an intermediary role in these O-GlcNAc mediated dysfunctions. However, Fülöp et al. (2007) only observed increased O-GlcNAc levels in high molecular weight proteins $(\geq 205 \mathrm{kDa})$, much greater in weight than CaMKII $(\sim 50-60 \mathrm{kDa})$. Considering the data of Fülöp et al. (2007) it would be prudent to investigate the interplay between CaMKII and high weight molecular proteins (such as ion channels) that may be contributing to arrhythmogenesis in DM.

Many of the cardiac pathologies influenced by O-GlcNAcCaMKII seem to be alleviated by inhibition of either O-GlcNAcylation generally, or a more specific targeting of O-GlcNAc-modified CaMKII. Erickson et al. (2013) showed that both a direct genetic target of the CaMKII O-GlcNAc site (S279) was able to completely prevent glucose-induced CaMKII autonomous activation, along with acute treatment with DON (an inhibitor of the HBP) was able to prevent O-GlcNAc modification of CaMKII. DON treatment was able to reduce glucose-induced arrhythmia incidence and score in an in vivo diabetic rat model to a similar level as KN-93, showing the importance of both O-GlcNAc modification and CaMKII activation in diabetic arrhythmogenesis (Erickson et al., 2013). The cellular arrhythmia observed by Hegyi et al. (2019) in diabetic mouse cardiomyocytes was prevented by either acute inhibition of O-GlcNAcylation or genetic inhibition of either CaMKII or the O-GlcNAcylation site on CaMKII. RamirezCorrea et al. (2015) found that removal of O-GlcNAcylation from myofilaments was able to restore myofilament function, showing that a more targeted approach of O-GlcNAc-CaMKII may prove beneficial in diabetic cardiomyopathy. By using a more targeted approach, a specific pathology (such as impaired myofilament $\mathrm{Ca}^{2+}$ sensitivity) may be effectively alleviated whilst also minimizing the potential of unintended side effects, given the physiological importance of O-GlcNAcylation in normal cellular function [for review, Butkinaree et al. (2010)].

\section{Calcium/Calmodulin (Ca2+/CaM) Dependent Protein Kinase II Oxidation and 0 -GIcNAcylation as Therapeutic Targets in the Diabetic Heart}

Despite evidence showing activation and subsequent arrhythmia resultant from both O-GlcNAcylated and oxidised CaMKII, the relative contributions of these mechanisms and the efficacy of targeting them as a therapeutic approach remains unclear. In this section, we will present experimental evidence for the potential benefits of targeting either O-GlcNAcylated or oxidised CaMKII as an approach to prevent cardiac pathology in the context of DM.

Considering the extensive role ox-CaMKII plays in cardiac pathologies and the increased prevalence of oxidative stress in the diabetic heart, ox-CaMKII presents a tantalizing target to alleviate the morbidity resultant from oxidative stress in the diabetic milieu. Indeed, blocking ox-CaMKII preserved the physiological fight/flight response whilst eliminating the increased risk of death from myocardial infarction in diabetic mice (Luo et al., 2013), highlighting the potential therapeutic benefit of blocking ox-CaMKII in a clinical setting. In a whole mouse model lacking functional NADPH oxidase or with CaMKII inhibition, mice were highly resistant to sinus node dysfunction induced by angiotensin II infusion, suggesting that CaMKII plays an important role in this pathway (Swaminathan et al., 2011) and further demonstrating the therapeutic benefit of a targeted approach focused on ox-CaMKII in DM.

Sommese et al. (2016) observed increased spontaneous $\mathrm{Ca}^{2+}$ release events associated with CaMKII-mediated phosphorylation of RyR2 in cardiomyocytes isolated from mice fed a fructose-rich diet (FRD) compared to control animals. Furthermore, ROS production and expression of oxCaMKII were significantly increased in FRD animals compared to control animals (Sommese et al., 2016). Treating FRD mice with an intracellular ROS scavenger or inhibition of CaMKII ablated this increase in spontaneous $\mathrm{Ca}^{2+}$ events and CaMKII phosphorylation of RyR2, leading the authors to conclude that ox-CaMKII is the main driver of arrhythmogenesis in this model, with any other activation of CaMKII (O-GlcNAcylation/ nitrosylation) playing a minor role. A more recent study examined the differential effects of oxidation and O-GlcNAcylation on AF, concluding that the loss of the oxidation site on CaMKII (M281/282) was sufficient to ablate AF susceptibility in mouse models of both type 1 and type 2 DM (Mesubi et al., 2020). Unexpectedly, the authors found that loss of the O-GlcNAcylation site on CaMKII (S280) was insufficient to prevent $\mathrm{AF}$ in both their type 1 and type $2 \mathrm{DM}$ mouse models. Acute inhibition of O-GlcNAcylation by pretreating mice with DON was able to protect against AF in T1DM, but not T2DM mice (Mesubi et al., 2020). The authors suggest that oxidation of 
CaMKII is the main driver of diabetic arrhythmogenesis, as opposed to a minor role of O-GlcNAcylation, particularly in T2DM. Considering the proximity of both the O-GlcNAcylation and oxidation sites on CaMKII, the authors made note that these modifications could be influencing each other, affecting the resultant arrhythmogenesis from either modification. The suggestion of interplay between O-GlcNAcylation and autophosphorylation of CaMKII (Erickson et al., 2013) provides precedent for this argument, which could be an interesting research avenue in the setting of DM.

Another body of published evidence instead supports O-GlcNAcylation as having a dominant role in diabetesinduced cardiac pathology. Lu et al. (2020) showed that ROS production resultant from high glucose is a downstream consequence of O-GlcNAcylation and CaMKII activation, as they observed a complete ablation of high glucose induced ROS production and $\mathrm{Ca}^{2+}$ sparks when cardiomyocytes were treated with CaMKII or HBP inhibitors (Fülöp et al., 2007). In direct contrast to Mesubi et al. (2020), they also showed that mutating the O-GlcNAcylation site on CaMKII is sufficient to prevent SR $\mathrm{Ca}^{2+}$ leak, whilst mutation of the oxidation site on CaMKII or inhibition of ROS production is insufficient to prevent spontaneous $\mathrm{Ca}^{2+}$ leak from the SR. One potential explanation for this discrepancy is that Mesubi et al. (2020) studied a diabetic model partially induced by streptozotocin (STZ) treatment (Hegyi et al., 2019), whilst Lu et al. (2020) examined a cardiomyocyte model incubated with high glucose and no STZ treatment for induction of diabetes (Fülöp et al., 2007). Recently, Hegyi et al. (2021a), Hegyi et al. (2021b) found that mutation of the CaMKII O-GlcNAcylation site significantly ablated the occurrence of arrhythmia in a diabetic hyperglycaemic mouse model, whilst preventing CaMKII oxidation had no effect during acute hyperglycaemia and only a minor effect in a mouse model of chronic diabetes.

Another study by Hegyi et al. (2020) supports the theory that O-GlcNAcylation and oxidation may be influencing each other, but it also emphasizes a more prominent role for O-GlcNAcylation of CaMKII in the context of diabetes. O-GlcNAcylated CaMKII was observed to alter $\mathrm{K}^{+}$channels currents, such as a reduction in $\mathrm{I}_{\text {to }}$ recovery and $\mathrm{I}_{\mathrm{K} 1}$ amplitude, which may contribute to arrhythmia in diabetes. $\mathrm{I}_{\text {to }}$ amplitude was also seen to be reduced in acute hyperglycaemia, although this effect was not dependent on O-GlcNAc-CaMKII, instead seeming to be regulated via a NOX2-ROS-PKC pathway.

The possibility also exists that O-GlcNAcylation may be affecting the diabetic heart in a CaMKII-independent manner. A recent study by Umapathi et al. (2021) showed that overexpression of OGT was able to induce cardiomyopathy and increases in $\mathrm{Ca}^{2+}$ spark frequency post-trans-aortic constriction in a mouse model. OGT-overexpressing mice also exhibited dramatically increased mortality rates compared with a control group; however, these effects were not alleviated by mutation of the O-GlcNAcylation site on CaMKII, S280 (Umapathi et al., 2021). Perhaps an effect unique of the diabetic state is influencing CaMKII activation by O-GlcNAcylation in the other discussed studies, as opposed to O-GlcNAcylation in a non-diabetic model. It remains an open question as to whether O-GlcNAcylation in diabetes is influencing cardiac mortality in a CaMKII-independent manner.

Rather than being solely regulated by either O-GlcNAcylation or oxidation, arrhythmogenesis in diabetes may be regulated by both modifications interacting with each other at different stages of the disease process. The complex nature of DM makes it seemingly improbable that a pathological process is regulated by one factor, instead the answer may lie within crosstalk of these two modifications, as well as others. Further targeted research to fully elucidate the mechanism(s) by which the diabetic milieu activates CaMKII and contributes to cardiac pathology is needed.

\section{S-Nitrosylation in Diabetes}

S-nitrosylation involves the PTM of protein thiols by nitric oxide (NO) and has recently emerged as a key regulator of cardiac signalling. $\mathrm{NO}$ is typically produced in the myocardium by various isoforms of $\mathrm{NO}$ synthase (NOS) and regulates a number of cardiac physiological processes [for review, Murphy et al. (2014)]. For instance, the interplay between NO and CaMKII is integral to mechanochemotransduction within cardiomyocytes (Jian et al., 2014). Regulation of NO production is impaired in diabetes and has been suggested to underlie the various vascular pathologies present in DM (Knapp et al., 2019). Interestingly, activation of the HBP impairs insulinmediated NOS activity (Federici et al., 2002), suggesting a role of O-GlcNAcylation in diabetes mediated NOS impairment.

NO provides a novel activation mechanism for CaMKII in cardiac tissue by directly adding an S-nitrosylation modification to the protein (Gutierrez et al., 2013). NO donors were able to increase $\mathrm{Ca}^{2+}$ spark frequency in cardiomyocytes, with this effect almost completely ablated by inhibiting CaMKII (Gutierrez et al., 2013). Erickson et al. (2015) provided further insight into interactions between $\mathrm{NO}$ and CaMKII, showing a novel dualregulation of CaMKII by NO. Nitrosylation of CaMKII at C290 resulted in autonomous activation of the enzyme, whilst nitrosylation at C273 inhibits CaMKII activity. The authors suggested that timing of $\mathrm{Ca}^{2+}$ release events could be a critical factor in determining whether CaMKII is activated or inhibited, due to $\mathrm{Ca}^{2+} / \mathrm{CaM}$ dependence of some NOS variants for NO production. Considering the well-studied changes in $\mathrm{Ca}^{2+}$ handling in DM, it would be an intriguing topic to investigate how DM influences CaMKII activation/inhibition by NO.

Enzymatic "uncoupling" of eNOS leads to a reduction in NO production and an increase in superoxide production. A reduction of $\mathrm{BH}_{4}$ levels, a cofactor essential for eNOS function, occurs in diabetes, which is associated with increased oxidative stress and reduced NO production (Alp et al., 2003). By increasing $\mathrm{BH}_{4}$ levels, oxidative stress is reduced and the loss of NO production is ameliorated (Alp et al., 2003). Along with a reduction in $\mathrm{BH}_{4}$ levels, increased $\mathrm{O}-\mathrm{GlcNAcylation}$ in diabetes is correlated with reduced Akt phosphorylation (Luo et al., 2008) which is responsible for eNOS activation (Du et al., 2001). Along with this, O-GlcNAcylation of eNOS is increased, which may result in decreased eNOS activity (Du et al., 2001).

Despite the myriad of studies showing reductions in $\mathrm{NO}$ production in diabetes, the focus of much of this research is on vascular rather than cardiac dysfunction. Considering the 


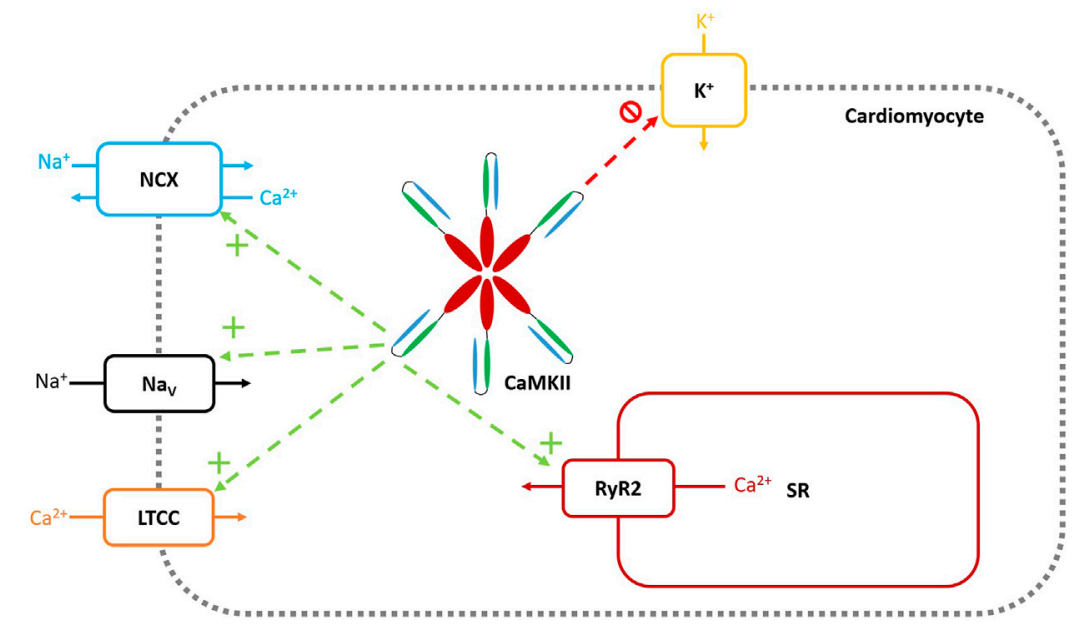

FIGURE 3 | Molecular Targets of CaMKII. Green arrows and + symbols represent CaMKII increasing functional activity of the target channel through either upregulation of channel numbers, or direct augmentation of channel activity. Red arrows and symbols represent CaMKII decreasing functional activity of the target channel. Veitch 2021, original work.

results of Erickson et al. (2015) and Gutierrez et al. (2013) concerning the dual-regulation of CaMKII by NO, it could be reasoned that this regulation is altered in diabetes due to disruptions in NO production, potentially contributing to cardiac dysfunction in DM via pathological changes in CaMKII activation. The involvement of nitrosylated-CaMKII in both inotropy and generation of spontaneous $\mathrm{Ca}^{2+}$ sparks and waves have been shown in non-diabetic models (Gutierrez et al., 2013; Curran et al., 2014; Pereira et al., 2017). Both of these phenomena have been well characterised to be upset in the diabetic milieu, however no research as of yet has investigated the role of nitrosylated-CaMKII in these events in DM.

\section{ARRHYTHMOGENIC TARGETS OF CALCIUM/CALMODULIN (CA2+/CAM) DEPENDENT PROTEIN KINASE II}

Diabetes has long been recognized as an independent risk factor for arrhythmogenesis (Benjamin et al., 1994) and the downstream arrhythmogenic effects of CaMKII following post-translational modification in diabetes have been discussed above. Mechanistically, CaMKII may lead to proarrhythmic consequences via early or delayed after depolarisations (EADs and DADs), which lead to triggered activity and subsequent arrhythmia, such as atrial fibrillation [for review, Mustroph et al. (2017)]. EADs involve an early, secondary depolarisation prior to repolarization of the action potential, resultant from reopening of L-type $\mathrm{Ca}^{2+}$ channels (LTCC) (Dobrev and Wehrens, 2017). DADs occur following a full repolarization of the action potential, resultant from spontaneous $\mathrm{Ca}^{2+}$ release from the SR. CaMKII affects the development of arrhythmia via a plethora of different molecular targets, some of which will be discussed below. These molecular targets are summarised in Figure 3.

\section{$\mathrm{Na}^{+}$Channels}

Voltage gated $\mathrm{Na}^{+}$channels $\left(\mathrm{Na}_{\mathrm{V}}\right)$ play an integral role in normal cardiac physiology, allowing for rapid $\mathrm{Na}^{+}$entry into cardiomyocytes, resulting in the upstroke of the cardiac action potential, followed by fast inactivation allowing for repolarization (for review Marban et al. (1998)]. Alterations in this $\mathrm{Na}^{+}$current through $\mathrm{Na}_{\mathrm{V}}$ channel modification can have arrhythmogenic consequences, such as increasing the late $\mathrm{Na}^{+}$current $\left(\mathrm{I}_{\mathrm{Na}}\right)$ or altering channel expression, leading to arrhythmia (Yu et al., 2018).

Oxidised CaMKII contributes to heightened late $\mathrm{I}_{\mathrm{Na}}$ following activation of the renin-angiotensin system, resulting in generation of early after depolarisations (EADs) leading to increased propensity for cellular arrhythmia in isolated rabbit ventricular myocytes (Zhao et al., 2011). In a similar rabbit ventricular myocyte model, Ma et al. (2012) showed that inhibition of both PKC and CaMKII was able to prevent heightened late $\mathrm{I}_{\mathrm{Na}}$ following $\mathrm{Ca}^{2+}$ overload, suggesting that multiple kinases may play a role in arrhythmias associated with late $\mathrm{I}_{\mathrm{Na}}$. Howard et al. (2018) showed that this heightened late $\mathrm{I}_{\mathrm{Na}}$ occurs in other disease states such as $\mathrm{I} / \mathrm{R}$ injury in a mouse Langendorff model, proposing that CaMKII is directly hyperphosphorylating $\mathrm{Na}_{\mathrm{V}} 1.5$ leading to spontaneous arrhythmogenic events in I/R injury. Lebek et al. (2020) was able to expand upon these previous animal studies, showing increased phosphorylation of $\mathrm{Na}_{\mathrm{V}} 1.5$ in atrial myocytes from human patients with sleep disordered breathing. Atrial myocytes from these patients exhibited heightened late $\mathrm{I}_{\mathrm{Na}}$, which was reversed by acute inhibition of CaMKII (Lebek et al., 2020). Late $\mathrm{I}_{\mathrm{Na}}$ is heightened in diabetes, contributing to the arrhythmogenic substrate ( $\mathrm{Lu}$ et al., 2013; Jin et al., 2019), which may be another pathway by which CaMKII influences arrhythmogenesis in DM. In an obese mouse model, ablation of the modification site by CaMKII on cardiac $\mathrm{Na}_{\mathrm{V}} 1.5$ was able to both reduce arrhythmogenesis and alleviate cardiac remodeling 
(Dewal et al., 2021). To the best of our knowledge, no study to date has examined the role of CaMKII in modulating cardiac $\mathrm{Na}_{\mathrm{V}}$ in DM. These studies highlight the importance of $\mathrm{Na}_{V}$ in both normal physiological function and the importance of dysregulation of these channels in disease states resultant from modulation by CaMKII.

\section{Cardiac Ryanodine Receptor}

The cardiac ryanodine receptor (RyR2) is integrally involved in cardiac ECC via the process of $\mathrm{Ca}^{2+}$ induced $\mathrm{Ca}^{2+}$ release (CICR). Depolarisation of the cardiomyocyte leads to $\mathrm{Ca}^{2+}$ influx via LTCC. This initial $\mathrm{Ca}^{2+}$ influx triggers RyR2 on the sarcoplasmic reticulum (SR) membrane to release $\mathrm{Ca}^{2+}$ stored within the SR, providing enough $\mathrm{Ca}^{2+}$ for cardiac contraction [for review, Wehrens and Marks (2003)]. CaMKII regulates RyR2 via phosphorylation (Wehrens et al., 2004), which may play an integral role in arrhythmogenesis during various disease states.

CaMKII phosphorylation of RyR2 increases $\mathrm{Ca}^{2+}$ leak from the SR, resulting in an increased propensity for arrhythmogenic events. CaMKII-mediated RyR2 $\mathrm{Ca}^{2+}$ leak is involved in arrhythmogenesis in a large variety of pathological states, including Duchenne muscular dystrophy (Ather et al., 2013), chronic $\beta$-adrenergic stimulation (Grimm et al., 2015), atrial fibrillation (Chelu et al., 2009) and arrhythmias resultant from cardiac glycoside treatment (Gonano and Petroff, 2014). This CaMKII-mediated SR $\mathrm{Ca}^{2+}$ leak may even play a role in apoptotic pathways, with this effect heightened during situations of hyperglycaemia (Federico et al., 2017). In T2DM rat hearts, CaMKII-mediated SR hyperphosphorylation enhances SR Ca ${ }^{2+}$ leak, increasing the propensity for DADs, and thus arrhythmia (Popescu et al., 2019).

A recent mathematical modelling study shows a potential relationship between $\mathrm{Na}_{V}, \mathrm{RyR} 2$ and CaMKII. CaMKIIdependent increases in late $\mathrm{I}_{\mathrm{Na}}$ lead to increased intracellular $\mathrm{Ca}^{2+}$ via reverse-mode $\mathrm{Na}^{+} / \mathrm{Ca}^{2+}$ exchanger (NCX) activity, resulting in further enhanced CaMKII activity and an increased RyR2 open probability (Onal et al., 2017). This study shows the potential for various arrhythmogenic pathways/targets to synergise with each other in pathological situations, leading to positive feedback loops and heightening the risk for an arrhythmogenic event. Voigt et al. (2012) showed evidence of heightened $\mathrm{Ca}^{2+}$ spark frequency, increased opening probability of RyR2 and greater $\mathrm{I}_{\mathrm{NCX}}$ in human AF myocytes. Inhibiting CaMKII was able to normalise the increased SR $\mathrm{Ca}^{2+}$ leak and reduce the opening probability of RyR2 (Voigt et al., 2012). As increased cytosolic $\mathrm{Ca}^{2+}$ activates forward-mode NCX, the authors suggest that the interplay between CaMKII, RyR2 and NCX results in the heightened $\mathrm{Ca}^{2+}$ spark frequency and $\mathrm{DaDs}$ in human AF myocytes.

\section{$\mathrm{Na}^{+} / \mathrm{Ca}^{2+}$ Exchanger}

Along with its interplay with RyR2 in arrhythmogenesis, CaMKII may play a role in directly or indirectly facilitating the arrhythmogenic transient inward current $\left(\mathrm{I}_{\mathrm{ti}}\right)$. Inhibition of CaMKII was able to prevent an NCX mediated $\mathrm{I}_{\mathrm{ti}}$ in isolated rabbit ventricular myocytes, which may help prevent $\mathrm{Ca}^{2+}$ overload induced arrhythmia (Wu et al., 1999a). In an
STZ-induced DM rat model, NCX protein expression is increased in atrial tissue, which was ameliorated by antioxidant treatment (Yang et al., 2020). This antioxidant treatment also alleviated the raised levels of phosphorylated CaMKII seen in this diabetic model. The authors concluded from these findings that CaMKII may be involved in regulation of NCX expression in diabetes, which could provide another pathway by which CaMKII increases arrhythmogenesis in diabetic patients. A recent study by Al Kury et al. (2021) in a similar STZ-induced DM rat model identified increased $\mathrm{Ca}^{2+}$ transient amplitudes in diabetic ventricular myocytes. This was accompanied with a significant impairment of NCX current amplitude in the diabetic cells. Increased amplitudes of $\mathrm{Ca}^{2+}$ transients may lead to the increased arrhythmia seen in both diabetic animal models and human patients.

\section{L-Type $\mathrm{Ca}^{2+}$ Channels}

LTCC plays a crucial role in cardiac ECC, allowing influx of $\mathrm{Ca}^{2+}$ into the cardiomyocyte following membrane depolarisation. CaMKII regulates sino-atrial node pacemaker cells by modulating LTCC. Inhibition of CaMKII reduced LTCC current by $50 \%$ and even prevented spontaneous excitations from these cells at high concentrations of KN-93 (Vinogradova et al., 2000). Wu et al. (1999b) also showed CaMKII-mediated augmentation of LTCC current, along with evidence that inhibiting CaMKII prevented EADs resultant from slow pacing and decreased extracellular $\mathrm{K}^{+}$, which the authors suggest is due to CaMKII-mediated augmentation of LTCC current, leading to arrhythmia. However, the authors do not conclusively show that this effect is purely due to LTCC augmentation. Ox-CaMKII has also been shown to interact with the LTCC, which may lead to pathological consequences resultant from intracellular $\mathrm{Ca}^{2+}$ accumulation (Song et al., 2010). Angiotensin-II induces EADs and CaMKII activation by ROS in isolated ventricular myocytes, with augmentation of both LTCC current and late $\mathrm{I}_{\mathrm{Na}}$ potentially underlying the increased propensity of EAD generation (Zhao et al., 2011). Based on the evidence for CaMKII modulating LTCC as previously discussed, this may be a key link between angiotensin-II and the augmentation of LTCC current. Diabetes may impair the functionality of the LTCC, and the impaired $\mathrm{Ca}^{2+}$ current of the channels has been purported to underlie the contractile dysfunction seen in a T2DM mouse cardiomyocyte model (Pereira et al., 2006). This impairment does not seem to persist in an STZ-induced T1DM rat model, with no significant difference between LTCC currents from diabetic and control animals (Al Kury et al., 2021). The role of CaMKII in regulation of LTCC during diabetes remains unclear and would benefit from further investigation.

\section{$\mathrm{K}^{+}$Channels}

Maintenance of a stable repolarization period is essential for normal cardiac function and maintenance of the cardiac action potential, as alterations in this repolarization period can lead to arrhythmia. $\mathrm{K}^{+}$channels are essential for maintaining a stable resting membrane potential and termination of the AP in cardiomyocytes [for review, Ravens and Cerbai (2008)]. 
TABLE 1 | Relevant literature.

\begin{tabular}{|c|c|c|c|c|c|}
\hline First author & Journal published & Reference number & Date & Model & $\begin{array}{l}\text { Arrhythmogenic events } \\
\text { examined }\end{array}$ \\
\hline Hegyi B & Circulation research & $\begin{array}{l}\text { Hegyi et al. (2021a), } \\
\text { Hegyi et al. (2021b) }\end{array}$ & 2021 & $\begin{array}{l}\text { LV mouse cardiomyocytes (high glucose) } \\
\text { In-vivo ECG of STZ mice }\end{array}$ & $\begin{array}{l}\mathrm{Ca}^{2+} \text { spark and wave frequency } \\
\text { Action Potential Duration (APD) } \\
\text { DADs } \\
\text { Spontaneous Action Potentials } \\
\text { Arrhythmia susceptibility following } \\
\text { Caffeine/lsoproterenol challenge }\end{array}$ \\
\hline Hegyi B & Cardiovascular research & $\begin{array}{l}\text { Hegyi et al. (2021a), } \\
\text { Hegyi et al. (2021b) }\end{array}$ & 2021 & $\begin{array}{l}\text { Atrial and ventricular cardiomyocytes from mice } \\
\text { and rabbits (high glucose) }\end{array}$ & $\begin{array}{l}\mathrm{Na}^{+} \text {current } \\
\text { Impulse propagation } \\
\text { APD and STV (short term variability) } \\
\mathrm{Ca}^{2+} \text { spark and wave frequency } \\
\text { DADs }\end{array}$ \\
\hline Hegyi B & $\begin{array}{l}\text { Basic research in } \\
\text { Cardiology }\end{array}$ & Hegyi et al. (2020) & 2020 & $\begin{array}{l}\text { LV cardiomyocytes (rat, rabbit and mice) } \\
\text { STZ, high fat diet and db/db mice }\end{array}$ & Effects on $\mathrm{K}^{+}$channel current \\
\hline Yang $Y$ & Life Sciences & Yang et al. (2020) & 2020 & Electrophysiology of isolated STZ rat hearts & $\begin{array}{l}\text { Conduction inhomogeneity } \\
\text { Conduction velocity } \\
\text { Inducible AF }\end{array}$ \\
\hline Lu S & Circulation research & Lu et al. (2020) & 2020 & $\begin{array}{l}\text { High glucose mouse ventricular } \\
\text { cardiomyocytes } \\
\text { High glucose hiPSC-CMs }\end{array}$ & $\mathrm{Ca}^{2+}$ wave and spark frequency \\
\hline Popescu I & Heart rhythm & Popescu et al. (2019) & 2019 & $\begin{array}{l}\text { Surface ECG and isolated ventricular } \\
\text { cardiomyocytes from HIP rats }\end{array}$ & $\begin{array}{l}\text { Arrhythmia susceptibility following } \\
\text { Caffeine/Dobutamine challenge } \\
\text { DAD incidence } \\
\mathrm{Ca}^{2+} \text { spark frequency }\end{array}$ \\
\hline Soliman $\mathrm{H}$ & $\begin{array}{l}\text { International journal of } \\
\text { Cardiology }\end{array}$ & Soliman et al. (2019) & 2019 & $\begin{array}{l}\text { Isolated ventricular cardiomyocytes from STZ } \\
\text { mice and STZ rats }\end{array}$ & $\begin{array}{l}\mathrm{Ca}^{2+} \text { transients } \\
\mathrm{SR} \mathrm{Ca}{ }^{2+} \text { leak }\end{array}$ \\
\hline Monnerat G & Nature Communications & Monnerat et al. (2016) & 2016 & $\begin{array}{l}\text { Ventricular cardiomyocytes, LV muscle strips } \\
\text { and in-vivo ECG of STZ mice and STZ rats }\end{array}$ & $\begin{array}{l}\text { AP prolongation } \\
\mathrm{Ca}^{2+} \text { spark frequency } \\
\text { Arrhythmia susceptibility following } \\
\text { Caffeine/Dobutamine challenge } \\
\text { I }_{\text {to }} \text { current }\end{array}$ \\
\hline Sommese L & $\begin{array}{l}\text { International journal of } \\
\text { Cardiology }\end{array}$ & Sommese et al. (2016) & 2016 & $\begin{array}{l}\text { Surface ECG and isolated ventricular } \\
\text { cardiomyocytes from fructose rich diet rats } \\
\text { (prediabetes) }\end{array}$ & $\begin{array}{l}\text { Spontaneous } \mathrm{Ca}^{2+} \text { release events } \\
\text { Spontaneous contractions } \\
\text { Synchronicity of } \mathrm{Ca}^{2+} \text { release events } \\
\mathrm{Ca}^{2+} \text { wave frequency }\end{array}$ \\
\hline Rolim N & $\begin{array}{l}\text { Basic research in } \\
\text { Cardiology }\end{array}$ & Rolim et al. (2015) & 2015 & $\begin{array}{l}\text { Ventricular intracardiac electrogram and LV } \\
\text { cardiomyocytes from db/db mice }\end{array}$ & $\begin{array}{l}\text { Inducible vent. Tachycardia } \\
\text { Diastolic } \mathrm{Ca}^{2+} \text { leak } \\
\text { Increased inward current }\end{array}$ \\
\hline Erickson JR & Nature & Erickson et al. (2013) & 2013 & $\begin{array}{l}\text { Isolated HIP rat ventricular cardiomyocytes } \\
\text { Langendorff HIP rat hearts } \\
\text { In-vivo ECG of HIP rat hearts }\end{array}$ & $\begin{array}{l}\mathrm{Ca}^{2+} \text { wave and spark frequency } \\
\text { PVCs } \\
\text { Arrhythmia susceptibility following } \\
\text { Caffeine/Dobutamine challenge }\end{array}$ \\
\hline Tuncay E & $\begin{array}{l}\text { Journal of bioenergetics } \\
\text { and biomembranes }\end{array}$ & Tuncay et al. (2011) & 2011 & $\begin{array}{l}\text { Papillary muscle strips and isolated ventricular } \\
\text { cardiomyocytes from STZ rats }\end{array}$ & Action potential duration \\
\hline
\end{tabular}

O-GlcNAcylated CaMKII modulates cardiac $\mathrm{K}^{+}$channels through reducing transient outward $\mathrm{K}^{+}$current $\left(\mathrm{I}_{\mathrm{to}}\right)$ and enhancing $\mathrm{I}_{\text {to }}$ recovery from inactivation and increased inward rectifier $\mathrm{K}^{+}$current $\left(\mathrm{I}_{\mathrm{K} 1}\right)$ (Hegyi et al., 2019; Hegyi et al., 2020), which contributes to arrhythmogenesis. Hegyi et al. (2020) further showed CaMKII is involved in downregulating expression of many of these $\mathrm{K}^{+}$channels. In an acute hyperglycaemic mouse myocyte model of diabetes, Hegyi et al. (2019) showed that CaMKII and O-GlcNAcylation are necessary for the impairment seen on $\mathrm{K}^{+}$channel function in DM. Contrasting this, an STZ-induced rat diabetic model showed that CaMKII was unable to regulate $\mathrm{I}_{\text {to }}$ inactivation in this model (Gallego et al., 2008). The differing effects of CaMKIImediated $\mathrm{K}^{+}$channel regulation in these two models highlight the issues in extrapolating results from $\mathrm{T} 1$ to $\mathrm{T} 2 \mathrm{DM}$ models.

\section{CALCIUM/CALMODULIN (CA2+/CAM) DEPENDENT PROTEIN KINASE II, CONTRACTILITY AND EXCITATION CONTRACTION COUPLING IN DIABETES}

\section{Calcium/Calmodulin (Ca2+/CaM) Dependent Protein Kinase II and Diabetic Contractility}

CaMKII also influences the impaired cardiac contractility seen in diabetes, as inhibition of the enzyme was able to restore force and rate of contraction in diabetic rat cardiac tissue (Daniels et al., 2018). Interestingly, Daniels et al. (2018) noted increased levels of O-GlcNAc modified CaMKII in human diabetic cardiac tissue. Along with findings showing that reduction of O-GlcNAc 
modification in the diabetic heart can improve contractile function (Hu et al., 2005), this suggests that O-GlcNAcCaMKII may be playing an integral role in depressed diabetic cardiac contractile function. Further supporting these findings, a recent study by Hegyi et al. (2021a), Hegyi et al. (2021b) identified that O-GlcNAcylated CaMKII may be integral to the diastolic dysfunction seen in diabetes.

O-GlcNAc-CaMKII may not be the only modification of CaMKII resultant in contractile dysfunction in diabetes. Silberman et al. (2010) suggests that uncoupling of cardiac NOS mediates diastolic dysfunction. As previously discussed, NOS is known to be uncoupled in diabetes (Alp et al., 2003) leading to impaired NO production and increased levels of oxidative stress. Impairments in cardiac relaxation are a hallmark of diabetes (Fein et al., 1980; Lamberts et al., 2014; Daniels et al., 2018), so uncoupled NOS could be influencing modification of CaMKII by both nitrosylation and oxidation, contributing to the contractile dysfunction seen in diabetes.

An interaction between high glucose and oxidative stress may also be playing a role in the impaired contractility seen in the diabetic heart. Bhatt et al. (2015) observed depressed cardiac contractility resultant from high glucose conditions in T2DM ZDF rat trabeculae, which was alleviated with palmitate treatment. This palmitate treatment was able to prevent increased oxidative stress brought about by high glucose, suggesting a link between the two conditions. Considering the findings of Lu et al. (2020) that CaMKII and O-GlcNAcylation were integral to ROS production in murine ventricular myocytes, it is plausible that an interaction between high glucose, oxidative stress and CaMKII could be influencing the depressed contractility seen in DM.

\section{Calcium/Calmodulin (Ca2+/CaM) Dependent Protein Kinase II and Excitation Contraction Coupling in Diabetic Cardiomyopathy}

CaMKII is well known to influence various processes in ECC, as highlighted in Arrhythmogenic Targets of Calcium/Calmodulin $(\mathrm{Ca} 2+/ \mathrm{CaM})$ Dependent Protein Kinase II section discussing the various channels targeted by CaMKII which may lead to arrhythmogenesis [for review, Maier and Bers (2002)]. Studies have shown impairments of ECC in DM, such as impaired contraction and relaxation in isolated T1DM rat ventricular myocytes, along with slower rates of $\mathrm{Ca}^{2+}$ decay (Ren and Bode, 2000). T2DM mice hearts exhibit an increased $\mathrm{O}_{2}$ consumption from ECC, which may be contributing to impaired cardiac efficiency (Boardman et al., 2009). These impairments affect synchrony of ECC in the cardiomyocyte, with investigators observing asynchronous $\mathrm{Ca}^{2+}$ release along the length of diabetic cardiomyocytes, concomitant with a reduced density of T-tubules in a T2DM mouse model (Stølen et al., 2009). Other investigators have also shown no such impairments in ECC in a T2DM rat model, despite alteration in mRNA expression of various cardiac muscle proteins (Salem et al., 2013).
It remains unclear whether CaMKII is involved in ECC impairments in diabetes, although Stølen et al. (2009) observed hyperphosphorylated CaMKII present in a T2DM mouse model, though did not link CaMKII to the ECC dysfunction. Research on the interaction between CaMKII and ECC dysfunction in diabetes remains lacking, and would prove a valuable insight into the role of CaMKII in DCM.

\section{CONCLUDING STATEMENTS}

There is already substantial literature demonstrating a critical role for CaMKII in various diabetic cardiac pathologies, and further research in this field continues to emerge. Thus, CaMKII presents as an appealing treatment target for diabetic cardiomyopathy, allowing the hypothetical clinician to treat many of the downstream effects of DM with one targeted therapy. A variety of different CaMKII inhibitors have already been developed with the aim to produce such a therapy [for review, Nassal et al. (2020)], however, care must be taken to ensure the physiological roles of CaMKII are not upset with such a treatment.

An isoform-specific inhibitor of CaMKIIS (the main cardiac isoform of CaMKII) could be utilized to target the cardiac-specific pathology of autonomously activated CaMKII in diabetes, avoiding any off-target effects in other tissues, such as the $\alpha$ and $\beta$ isoforms of CaMKII and disruption of memory formation in the hippocampus (Buard et al., 2010). Lebek et al. (2018) recently showed that the novel CaMKII $\delta$ inhibitor GS-680 was able to reduce premature atrial contractions, DADs and EADs in human atrial tissue, showing promise for the anti-arrhythmic benefits of such an inhibitor in the clinical setting. However, this blunted arrhythmogenesis coincided with impaired contractile force in the atrial tissue (Lebek et al., 2018). This underscores the needto strike a balanceto ensure the essential physiological roles of CaMKII $\delta$ in the heart are not compromised with such a treatment, such as its roles in both ECC and exercise training (Burgos et al., 2017; Beckendorf et al., 2018).

Considering the increased susceptibility of diabetics to arrhythmia following ischaemic injury (Chou et al., 2020), it could be of benefit to examine the effects of CaMKII inhibition in the ischaemic diabetic heart. Altering levels of CaMKII activity/expression in ischaemic diabetic myocardium could have unforeseen effects if studies focus only on the diabetic myocardium. This "hidden cardiotoxicity" has had substantial negative impacts on clinical trials and pharmaceutical therapies to date (Ferdinandy et al., 2019), so care should be taken when developing prospective therapies for the diabetic heart.

Rather than a direct targeting of CaMKII, a prospective treatment may instead look to altering the autonomous activation pathways that have become oversaturated in diabetes, preventing hyperactive CaMKII at its source. Increased O-GlcNAcylation of CaMKII may underlie various contractile abnormalities, arrhythmogenesis and even ROS generation in DM, however the modification still plays an integral role in normal physiological function. Increased 
O-GlcNAcylation is even protective during I/R injury (Champattanachai et al., 2007) so removing this modification may have unintended consequences on other cardiac pathologies. The dual-regulation of CaMKII by S-Nitrosylation as characterised by Erickson et al. (2015) presents a challenging task to balance the activation of CaMKII by this modification, considering the complex links between nitrosylation and both pathological and physiological processes. Oxidation has long been recognised as a pathological modification, with aberrant oxidation of proteins underlying a swathe of cardiac pathologies. A treatment targeting this modification would also present its own unique challenges, considering the complex involvement of oxidation in various intracellular signalling pathways (Zhang and Shah, 2014). Targeting any one of these modifications presents as a double-edged sword: diabetic cardiac dysfunction may be prevented by altering levels of any given PTM, but such an approach would likely have undesirable offtarget effects on important physiological processes if a balance is not struck between too much and too little modification.

A recent clinical trial has examined the effects of CaMKII inhibition following anterior STEMI and is the first of its kind to examine the clinical effects of CaMKII inhibition following STEMI in human patients (Boyle et al., 2021). Despite not seeing any difference between placebo and treatment in terms of improved LV remodeling, the inhibitor appeared to be well tolerated and safe amongst the patient group. Considering the absence of adverse effects in this trial, it should hopefully pave the way for future studies to examine the effects of CaMKII inhibition in other conditions, such as DM.

Changes occurring between acute and chronic hyperglycaemia must also be considered when developing therapies for use in DM. The effects of CaMKII on cardiac $\mathrm{K}^{+}$channels differ in situations of acute compared to chronic diabetes (Hegyi et al., 2020). As such, it can be assumed that blocking CaMKII activation in a patient who has had diabetes for 1 year would have noticeably different effects than in a patient who has had diabetes for 10 years. On a similar note, prediabetes presents a unique opportunity to target CaMKII before overt diabetes develops. An STZ and HFD induced rat model of prediabetes exhibited diastolic dysfunction and cardiac hypertrophy, though without increased autophosphorylation of CaMKII (Koncsos et al., 2016). Targeting CaMKII before development of diabetes could allow for a preventative treatment, minimizing the overt damage to the cardiovascular system seen in DM. However, this study did not examine the impact of other activation pathways of CaMKII in this model. O-GlcNAcylation in the rat heart is observed to be

\section{REFERENCES}

Al Kury, L. T., Sydorenko, V., Smail, M. M., Qureshi, M. A., Shmygol, A., Papandreou, D., et al. (2021). Calcium Signaling in Endocardial and Epicardial Ventricular Myocytes from Streptozotocin-induced Diabetic Rats. J. Diabetes Investig. 12 (4), 493-500. doi:10.1111/jdi.13451

Alp, N. J., Mussa, S., Khoo, J., Cai, S., Guzik, T., Jefferson, A., et al. (2003). Tetrahydrobiopterin-dependent Preservation of Nitric Oxide-Mediated Endothelial Function in Diabetes by Targeted Transgenic GTP- increased even before the presentation of prediabetes, following ingestion of a high fat/carbohydrate "Western" diet (Medford et al., 2012). CaMKII PTMs may be of interest in the prediabetic heart and could present a novel treatment opportunity prior to development of DCM.

Exercise has well-known beneficial effects on reducing the risk of excess cardiovascular morbidity and mortality associated with DM (Zethelius et al., 2014), however, CaMKII inhibition may blunt the benefits of exercise training. CaMKII is involved in several of the beneficial effects brought on by exercise training. Accordingly, inhibition of the enzyme prevents many (but not all) of these benefits (Kaurstad et al., 2012). Parallels can be drawn here to $\beta$-blocker treatment regimens and the associated exercise intolerance (Head, 1999), which can result in significant lifestyle impact for patients. Cardiac inhibition of CaMKII would again have benefits in terms of preventing pathology associated with diabetic cardiomyopathy but may negatively impact the lifestyle of prospective patients due to the resulting exercise intolerance.

As highlighted in this review, CaMKII has emerged as a key nodal signal in various pathological pathways in DM. Table 1 summarizes a search for relevant literature on the website PubMed using the terms "CaMKII," "cardiac arrhythmia," and "diabetes" on the 30th of May 2021. The impact of DCM on the role of CaMKII in many pathways [such as gene transcription (McKinsey, 2007)] remains to be elucidated, and could provide further treatment targets than those already described in the literature. By targeting overactive CaMKII or its downstream signalling pathways, much of the aberrant cardiovascular effects of the enzyme may be attenuated, substantially improving cardiovascular health, and minimizing the overt mortality from CVD seen in DM patients.

\section{AUTHOR CONTRIBUTIONS}

$\mathrm{CV}$ wrote the initial drafts of the manuscript. AP and JE performed editing to generate the final manuscript, and JE funded the work.

\section{FUNDING}

This manuscript was supported by funding from the Royal New Zealand Marsden Fund (Project UOO1707).

Cyclohydrolase I Overexpression. J. Clin. Invest. 112 (5), 725-735. doi:10.1172/jci17786

Ather, S., Wang, W., Wang, Q., Li, N., Anderson, M. E., and Wehrens, X. H. T. (2013). Inhibition of CaMKII Phosphorylation of RyR2 Prevents Inducible Ventricular Arrhythmias in Mice with Duchenne Muscular Dystrophy. Heart Rhythm 10 (4), 592-599. doi:10.1016/ j.hrthm.2012.12.016

Beckendorf, J., van den Hoogenhof, M. M. G., and Backs, J. (2018). Physiological and Unappreciated Roles of CaMKII in the Heart. Basic Res. Cardiol. 113 (4), 29. doi:10.1007/s00395-018-0688-8 
Benjamin, E. J., Levy, D., Vaziri, S. M., D’Agostino, R. B., Belanger, A. J., and Wolf, P. A. (1994). Independent Risk Factors for Atrial Fibrillation in a PopulationBased Cohort. JAMA 271 (11), 840-844. doi:10.1001/ jama.1994.03510350050036

Bhatt, N. M., Aon, M. A., Tocchetti, C. G., Shen, X., Dey, S., Ramirez-Correa, G., et al. (2015). Restoring Redox Balance Enhances Contractility in Heart Trabeculae from Type 2 Diabetic Rats Exposed to High Glucose. Am. J. Physiology-Heart Circulatory Physiol. 308 (4), H291-H302. doi:10.1152/ ajpheart.00378.2014

Boardman, N., Hafstad, A. D., Larsen, T. S., Severson, D. L., and Aasum, E. (2009). Increased O2 Cost of Basal Metabolism and Excitation-Contraction Coupling in Hearts from Type 2 Diabetic Mice. Am. J. Physiology-Heart Circulatory Physiol. 296 (5), H1373-H1379. doi:10.1152/ajpheart.01264.2008

Boudina, S., Sena, S., Theobald, H., Sheng, X., Wright, J. J., Hu, X. X., et al. (2007). Mitochondrial Energetics in the Heart in Obesity-Related Diabetes: Direct Evidence for Increased Uncoupled Respiration and Activation of Uncoupling Proteins. Diabetes 56 (10), 2457-2466. doi:10.2337/db07-0481

Boyle, A. J., Schultz, C., Selvanayagam, J. B., Moir, S., Kovacs, R., Dib, N., et al. (2021). Calcium/Calmodulin-Dependent Protein Kinase II Delta Inhibition and Ventricular Remodeling after Myocardial Infarction: A Randomized Clinical Trial. JAMA Cardiol. 6, 762-768. doi:10.1001/jamacardio.2021.0676

Buard, I., Coultrap, S. J., Freund, R. K., Lee, Y.-S., Dell'Acqua, M. L., Silva, A. J., et al. (2010). CaMKII "autonomy" Is Required for Initiating but Not for Maintaining Neuronal Long-Term Information Storage. J. Neurosci. 30 (24), 8214-8220. doi:10.1523/jneurosci.1469-10.2010

Burgos, J. I., Yeves, A. M., Barrena, J. P., Portiansky, E. L., Vila-Petroff, M. G., and Ennis, I. L. (2017). Nitric Oxide and CaMKII: Critical Steps in the Cardiac Contractile Response to IGF-1 and Swim Training. J. Mol. Cell Cardiol. 112, 16-26. doi:10.1016/j.yjmcc.2017.08.014

Butkinaree, C., Park, K., and Hart, G. W. (2010). O-linked $\beta$-N-acetylglucosamine (O-GlcNAc): Extensive Crosstalk with Phosphorylation to Regulate Signaling and Transcription in Response to Nutrients and Stress. Biochim. Biophys. Acta (Bba) - Gen. Subjects 1800 (2), 96-106. doi:10.1016/j.bbagen.2009.07.018

Champattanachai, V., Marchase, R. B., and Chatham, J. C. (2007). Glucosamine Protects Neonatal Cardiomyocytes from Ischemia-Reperfusion Injury via Increased Protein-Associated O-GlcNAc. Am. J. Physiology-Cell Physiol. 292 (1), C178-C187. doi:10.1152/ajpcell.00162.2006

Chelu, M. G., Sarma, S., Sood, S., Wang, S., van Oort, R. J., Skapura, D. G., et al. (2009). Calmodulin Kinase II-Mediated Sarcoplasmic Reticulum Ca2+ Leak Promotes Atrial Fibrillation in Mice. J. Clin. Invest. 119 (7), 1940-1951. doi:10.1172/jci37059

Chou, C-C., Lee, H-L., Chang, G-J., Wo, H-T., Yen, T-H., Wen, M-S., et al. (2020). Mechanisms of Ranolazine Pretreatment in Preventing Ventricular Tachyarrhythmias in Diabetic $\mathrm{Db} / \mathrm{db}$ Mice with Acute Regional Ischemia-Reperfusion Injury. Scientific Rep. 10 (1), 20032. doi:10.1038/ s41598-020-77014-0

Clark, R. J., McDonough, P. M., Swanson, E., Trost, S. U., Suzuki, M., Fukuda, M., et al. (2003). Diabetes and the Accompanying Hyperglycemia Impairs Cardiomyocyte Calcium Cycling through Increased Nuclear O-GlcNAcylation. J. Biol. Chem. 278 (45), 44230-44237. doi:10.1074/ jbc.m303810200

Curran, J., Tang, L., Roof, S. R., Velmurugan, S., Millard, A., Shonts, S., et al. (2014). Nitric Oxide-dependent Activation of CaMKII Increases Diastolic Sarcoplasmic Reticulum Calcium Release in Cardiac Myocytes in Response to Adrenergic Stimulation. PLoS One 9 (2), e87495. doi:10.1371/ journal.pone.0087495

Daniels, L., Bell, J. R., Delbridge, L. M. D., McDonald, F. J., Lamberts, R. R., and Erickson, J. R. (2015). The Role of CaMKII in Diabetic Heart Dysfunction. Heart Fail. Rev. 20 (5), 589-600. doi:10.1007/s10741-015-9498-3

Daniels, L. J., Wallace, R. S., Nicholson, O. M., Wilson, G. A., McDonald, F. J., Jones, P. P., et al. (2018). Inhibition of Calcium/calmodulin-dependent Kinase II Restores Contraction and Relaxation in Isolated Cardiac Muscle from Type 2 Diabetic Rats. Cardiovasc. Diabetology 17 (1), 89. doi:10.1186/s12933-0180732-x

Dewal, R. S., Greer-Short, A., Lane, C., Nirengi, S., Manzano, P. A., HernándezSaavedra, D., et al. (2021). Phospho-ablation of Cardiac Sodium Channel Nav1.5 Mitigates Susceptibility to Atrial Fibrillation and Improves Glucose
Homeostasis under Conditions of Diet-Induced Obesity. Int. J. Obes. 45 (4), 795-807. doi:10.1038/s41366-021-00742-4

Dobrev, D., and Wehrens, X. H. T. (2017). Calcium-mediated Cellular Triggered Activity in Atrial Fibrillation. J. Physiol. 595 (12), 4001-4008. doi:10.1113/ jp273048

Du, X. L., Edelstein, D., Dimmeler, S., Ju, Q., Sui, C., and Brownlee, M. (2001). Hyperglycemia Inhibits Endothelial Nitric Oxide Synthase Activity by Posttranslational Modification at the Akt Site. J. Clin. Invest. 108 (9), 1341-1348. doi:10.1172/jci11235

Erickson, J. R. (2014). Mechanisms of CaMKII Activation in the Heart. Front. Pharmacol. 5, 59. doi:10.3389/fphar.2014.00059

Erickson, J. R., and Anderson, M. E. (2008). CaMKII and its Role in Cardiac Arrhythmia. J. Cardiovasc. Electrophysiol. 19 (12), 1332-1336. doi:10.1111/ j.1540-8167.2008.01295.x

Erickson, J. R., Joiner, M.-l. A., Guan, X., Kutschke, W., Yang, J., Oddis, C. V., et al. (2008). A Dynamic Pathway for Calcium-independent Activation of CaMKII by Methionine Oxidation. Cell 133 (3), 462-474. doi:10.1016/j.cell.2008.02.048

Erickson, J. R., Nichols, C. B., Uchinoumi, H., Stein, M. L., Bossuyt, J., and Bers, D. M. (2015). S-nitrosylation Induces Both Autonomous Activation and Inhibition of Calcium/Calmodulin-dependent Protein Kinase II $\delta$. J. Biol. Chem. 290 (42), 25646-25656. doi:10.1074/jbc.m115.650234

Erickson, J. R., Pereira, L., Wang, L., Han, G., Ferguson, A., Dao, K., et al. (2013). Diabetic Hyperglycaemia Activates CaMKII and Arrhythmias by O-Linked Glycosylation. Nature 502 (7471), 372-376. doi:10.1038/nature12537

Federici, M., Menghini, R., Mauriello, A., Hribal, M. L., Ferrelli, F., Lauro, D., et al. (2002). Insulin-dependent Activation of Endothelial Nitric Oxide Synthase Is Impaired by O-Linked Glycosylation Modification of Signaling Proteins in Human Coronary Endothelial Cells. Circulation 106 (4), 466-472. doi:10.1161/ 01.cir.0000023043.02648.51

Federico, M., Portiansky, E. L., Sommese, L., Alvarado, F. J., Blanco, P. G., Zanuzzi, C. N., et al. (2017). Calcium-calmodulin-dependent Protein Kinase Mediates the Intracellular Signalling Pathways of Cardiac Apoptosis in Mice with Impaired Glucose Tolerance. J. Physiol. 595 (12), 4089-4108. doi:10.1113/ jp273714

Fein, F. S., Kornstein, L. B., Strobeck, J. E., Capasso, J. M., and Sonnenblick, E. H. (1980). Altered Myocardial Mechanics in Diabetic Rats. Circ. Res. 47 (6), 922-933. doi:10.1161/01.res.47.6.922

Ferdinandy, P., Baczkó, I., Bencsik, P., Giricz, Z., Görbe, A., Pacher, P., et al. (2019). Definition of Hidden Drug Cardiotoxicity: Paradigm Change in Cardiac Safety Testing and its Clinical Implications. Eur. Heart J. 40 (22), 1771-1777. doi:10.1093/eurheartj/ehy365

Fülöp, N., Mason, M. M., Dutta, K., Wang, P., Davidoff, A. J., Marchase, R. B., et al. (2007). Impact of Type 2 Diabetes and Aging on Cardiomyocyte Function and O-Linked N-Acetylglucosamine Levels in the Heart. Am. J. Physiology-Cell Physiol. 292 (4), C1370-C1378. doi:10.1152/ajpcell.00422.2006

Gallego, M., Fernández, D., Ahyayauch, H., Casis, E., and Casis, O. (2008). Reduced Calmodulin Expression Accelerates Transient Outward Potassium Current Inactivation in Diabetic Rat Heart. Cell Physiol Biochem 22 (5-6), 625-634. doi:10.1159/000185546

Garcia, M. J., McNamara, P. M., Gordon, T., and Kannell, W. B. (1974). Morbidity and Mortality in Diabetics in the Framingham Population: Sixteen Year FollowUp Study. Diabetes 23 (2), 105-111. doi:10.2337/diab.23.2.105

Gonano, L. A., and Petroff, M. V. (2014). Subcellular Mechanisms Underlying Digitalis-Induced Arrhythmias: Role of Calcium/calmodulin-dependent Kinase II (CaMKII) in the Transition from an Inotropic to an Arrhythmogenic Effect. Heart Lung Circ. 23 (12), 1118-1124. doi:10.1016/j.hlc.2014.07.074

Grimm, M., Ling, H., Willeford, A., Pereira, L., Gray, C. B. B., Erickson, J. R., et al. (2015). CaMKII $\delta$ Mediates $\beta$-adrenergic Effects on RyR2 Phosphorylation and SR Ca2+ Leak and the Pathophysiological Response to Chronic $\beta$-adrenergic Stimulation. J. Mol. Cell Cardiol. 85, 282-291. doi:10.1016/ j.yjmcc.2015.06.007

Gu, K., Cowie, C. C., and Harris, M. I. (1998). Mortality in Adults with and without Diabetes in a National Cohort of the U.S. Population, 1971-1993. Diabetes Care 21 (7), 1138-1145. doi:10.2337/diacare.21.7.1138

Gutierrez, D. A., Fernandez-Tenorio, M., Ogrodnik, J., and Niggli, E. (2013). NOdependent CaMKII Activation during $\beta$-adrenergic Stimulation of Cardiac Muscle. Cardiovasc. Res. 100 (3), 392-401. doi:10.1093/cvr/cvt201 
He, B. J., Joiner, M.-l. A., Singh, M. V., Luczak, E. D., Swaminathan, P. D., Koval, O. M., et al. (2011). Oxidation of CaMKII Determines the Cardiotoxic Effects of Aldosterone. Nat. Med. 17 (12), 1610-1618. doi:10.1038/nm.2506

Head, A. (1999). Exercise Metabolism and Beta-Blocker Therapy. An Update. Sports Med. 27 (2), 81-96. doi:10.2165/00007256-199927020-00002

Hegyi, B., Borst, J. M., Bailey, L. R. J., Shen, E. Y., Lucena, A. J., Navedo, M. F., et al. (2020). Hyperglycemia Regulates Cardiac K+ Channels via O-GlcNAc-CaMKII and NOX2-ROS-PKC Pathways. Basic Res. Cardiol. 115 (6), 71. doi:10.1007/ s00395-020-00834-8

Hegyi, B., Fasoli, A., Ko, C. Y., Van, B. W., Alim, C. C., Shen, E. Y., et al. (2021a). CaMKII Serine 280 O-GlcNAcylation Links Diabetic Hyperglycemia to Proarrhythmia. Circ. Res. 129, 98-113. doi:10.1161/CIRCRESAHA.120.318402

Hegyi, B., Ko, C. Y., Bossuyt, J., and Bers, D. M. (2021b). Two-hit Mechanism of Cardiac Arrhythmias in Diabetic Hyperglycaemia: Reduced Repolarization reserve, Neurohormonal Stimulation, and Heart Failure Exacerbate Susceptibility. Cardiovasc. Res. doi:10.1093/cvr/cvab006

Hegyi, B., Borst, J. M., Lucena, A. J., Bailey, L. R. J., Bossuyt, J., and Bers, D. M. (2019). Diabetic Hyperglycemia Regulates Potassium Channels and Arrhythmias in the Heart via Autonomous CaMKII Activation by O-Linked Glycosylation. Biophysical J. 116, 98a. doi:10.1016/j.bpj.2018.11.566

Ho, H.-T., Liu, B., Snyder, J. S., Lou, Q., Brundage, E. A., Velez-Cortes, F., et al. (2014). Ryanodine Receptor Phosphorylation by Oxidized CaMKII Contributes to the Cardiotoxic Effects of Cardiac Glycosides. Cardiovasc. Res. 101 (1), 165-174. doi:10.1093/cvr/cvt233

Hoch, B., Meyer, R., Hetzer, R., Krause, E.-G., and Karczewski, P. (1999). Identification and Expression of $\delta$-Isoforms of the Multifunctional $\mathrm{Ca} 2+/$ Calmodulin-dependent Protein Kinase in Failing and Nonfailing Human Myocardium. Circ. Res. 84 (6), 713-721. doi:10.1161/01.res.84.6.713

Howard, T., Greer-Short, A., Satroplus, T., Patel, N., Nassal, D., Mohler, P. J., et al. (2018). CaMKII-dependent Late Na+current Increases Electrical Dispersion and Arrhythmia in Ischemia-Reperfusion. Am. J. Physiology-Heart Circulatory Physiol. 315 (4), H794-h801. doi:10.1152/ajpheart.00197.2018

Hu, Y., Belke, D., Suarez, J., Swanson, E., Clark, R., Hoshijima, M., et al. (2005). Adenovirus-Mediated Overexpression of O -GlcNAcase Improves Contractile Function in the Diabetic Heart. Circ. Res. 96 (9), 1006-1013. doi:10.1161/ 01.res.0000165478.06813.58

Hudmon, A., and Schulman, H. (2002). Structure-function of the Multifunctional Ca2+/calmodulin-dependent Protein Kinase II. Biochem. J. 364 (Pt 3), 593-611. doi:10.1042/bj20020228

Jian, Z., Han, H., Zhang, T., Puglisi, J., Izu, L. T., Shaw, J. A., et al. (2014). Mechanochemotransduction during Cardiomyocyte Contraction Is Mediated by Localized Nitric Oxide Signaling. Sci. Signaling 7 (317), ra27. doi:10.1126/ scisignal.2005046

Jin, X., Jiang, Y., Xue, G., Yuan, Y., Zhu, H., Zhan, L., et al. (2019). Increase of Late Sodium Current Contributes to Enhanced Susceptibility to Atrial Fibrillation in Diabetic Mice. Eur. J. Pharmacol. 857, 172444. doi:10.1016/ j.ejphar.2019.172444

Kannel, W. B., and McGee, D. L. (1979). Diabetes and Glucose Tolerance as Risk Factors for Cardiovascular Disease: the Framingham Study. Diabetes Care 2 (2), 120-126. doi:10.2337/diacare.2.2.120

Kaurstad, G., Alves, M. N., Kemi, O. J., Rolim, N., Høydal, M. A., Wisløff, H., et al. (2012). Chronic CaMKII Inhibition Blunts the Cardiac Contractile Response to Exercise Training. Eur. J. Appl. Physiol. 112 (2), 579-588. doi:10.1007/s00421011-1994-0

Kessler, I. I. (1971). Mortality Experience of Diabetic Patients. Am. J. Med. 51 (6), 715-724. doi:10.1016/0002-9343(71)90299-3

Knapp, M., Tu, X., and Wu, R. (2019). Vascular Endothelial Dysfunction, a Major Mediator in Diabetic Cardiomyopathy. Acta Pharmacol. Sin 40 (1), 1-8. doi:10.1038/s41401-018-0042-6

Koncsos, G., Varga, Z. V., Baranyai, T., Boengler, K., Rohrbach, S., Li, L., et al. (2016). Diastolic Dysfunction in Prediabetic Male Rats: Role of Mitochondrial Oxidative Stress. Am. J. Physiology-Heart Circulatory Physiol. 311 (4), H927-H943. doi:10.1152/ajpheart.00049.2016

Lai, Y., Nairn, A. C., and Greengard, P. (1986). Autophosphorylation Reversibly Regulates the $\mathrm{Ca} 2+/$ calmodulin-Dependence of $\mathrm{Ca} 2+/$ calmodulin-dependent Protein Kinase II. Proc. Natl. Acad. Sci. 83 (12), 4253-4257. doi:10.1073/ pnas.83.12.4253
Lamberts, R. R., Lingam, S. J., Wang, H.-Y., Bollen, I. A., Hughes, G., Galvin, I. F., et al. (2014). Impaired Relaxation Despite Upregulated CalciumHandling Protein Atrial Myocardium from Type 2 Diabetic Patients with Preserved Ejection Fraction. Cardiovasc. Diabetol. 13, 72. doi:10.1186/1475-2840-13-72

Lebek, S., Pichler, K., Reuthner, K., Trum, M., Tafelmeier, M., Mustroph, J., et al. (2020). Enhanced CaMKII-dependent Late I Na Induces Atrial Proarrhythmic Activity in Patients with Sleep-Disordered Breathing. Circ. Res. 126 (5), 603-615. doi:10.1161/circresaha.119.315755

Lebek, S., Plößl, A., Baier, M., Mustroph, J., Tarnowski, D., Lücht, C. M., et al. (2018). The Novel CaMKII Inhibitor GS-680 Reduces Diastolic SR Ca Leak and Prevents CaMKII-dependent Pro-arrhythmic Activity. J. Mol. Cell Cardiol. 118, 159-168. doi:10.1016/j.yjmcc.2018.03.020

Ljubojevic-Holzer, S., Herren, A. W., Djalinac, N., Voglhuber, J., Morotti, S., Holzer, M., et al. (2020). CaMKIISC Drives Early Adaptive Ca 2+ Change and Late Eccentric Cardiac Hypertrophy. Circ. Res. 127 (9), 1159-1178. doi:10.1161/circresaha.120.316947

Lu, S., Liao, Z., Lu, X., Katschinski, D. M., Mercola, M., Chen, J., et al. (2020). Hyperglycemia Acutely Increases Cytosolic Reactive Oxygen Species via O-Linked GlcNAcylation and CaMKII Activation in Mouse Ventricular Myocytes. Circ. Res. 126, e80-e96. doi:10.1161/CIRCRESAHA.119.316288

Lu, Z., Jiang, Y.-P., Wu, C.-Y. C., Ballou, L. M., Liu, S., Carpenter, E. S., et al. (2013). Increased Persistent Sodium Current Due to Decreased PI3K Signaling Contributes to QT Prolongation in the Diabetic Heart. Diabetes 62 (12), 4257-4265. doi:10.2337/db13-0420

Luo, B., Soesanto, Y., and McClain, D. A. (2008). Protein Modification by O-Linked GlcNAc Reduces Angiogenesis by Inhibiting Akt Activity in Endothelial Cells. Atvb 28 (4), 651-657. doi:10.1161/atvbaha.107.159533

Luo, M., Guan, X., Luczak, E. D., Lang, D., Kutschke, W., Gao, Z., et al. (2013). Diabetes Increases Mortality after Myocardial Infarction by Oxidizing CaMKII. J. Clin. Invest. 123 (3), 1262-1274. doi:10.1172/jci65268

Ma, J., Luo, A., Wu, L., Wan, W., Zhang, P., Ren, Z., et al. (2012). Calmodulin Kinase II and Protein Kinase C Mediate the Effect of Increased Intracellular Calcium to Augment Late Sodium Current in Rabbit Ventricular Myocytes. Am. J. Physiology-Cell Physiol. 302 (8), C1141-C1151. doi:10.1152/ ajpcell.00374.2011

Maier, L. S., and Bers, D. M. (2002). Calcium, Calmodulin, and CalciumCalmodulin Kinase II: Heartbeat to Heartbeat and beyond. J. Mol. Cell Cardiol. 34 (8), 919-939. doi:10.1006/jmcc.2002.2038

Marban, E., Yamagishi, T., and Tomaselli, G. F. (1998). Structure and Function of Voltage-Gated Sodium Channels. J. Physiol. 508 (3), 647-657. doi:10.1111/ j.1469-7793.1998.647bp.x

McKinsey, T. A. (2007). Derepression of Pathological Cardiac Genes by Members of the CaM Kinase Superfamily. Cardiovasc. Res. 73 (4), 667-677. doi:10.1016/ j.cardiores.2006.11.036

Medford, H. M., Chatham, J. C., and Marsh, S. A. (2012). Chronic Ingestion of a Western Diet Increases O-Linked-Beta-N-Acetylglucosamine (O-GlcNAc) Protein Modification in the Rat Heart. Life Sci. 90 (23-24), 883-888. doi:10.1016/j.lfs.2012.04.030

Mesubi, O. O., Rokita, A. G., Abrol, N., Wu, Y., Chen, B., Wang, Q., et al. (2020). Oxidized-CaMKII and O-GlcNAcylation Cause Increased Atrial Fibrillation in Diabetic Mice by Distinct Mechanisms. J. Clin. Invest. 131, e95747. doi:10.1172/ JCI95747

Monnerat, G., Alarcon, M. L., Vasconcellos, L. R., Hochman-Mendez, C., Brasil, G., Bassani, R. A., et al. (2016). Macrophage-dependent IL-1beta Production Induces Cardiac Arrhythmias in Diabetic Mice. Nat. Commun. 7, 13344. doi:10.1038/ncomms 13344

Movahed, M.-R., Hashemzadeh, M., and Mazen Jamal, M. (2005). Diabetes Mellitus Is a strong, Independent Risk for Atrial Fibrillation and Flutter in Addition to Other Cardiovascular Disease. Int. J. Cardiol. 105 (3), 315-318. doi:10.1016/j.ijcard.2005.02.050

Murphy, E., Kohr, M., Menazza, S., Nguyen, T., Evangelista, A., Sun, J., et al. (2014). Signaling by S-Nitrosylation in the Heart. J. Mol. Cell Cardiol. 73, 18-25. doi:10.1016/j.yjmcc.2014.01.003

Murtaza, G., Virk, H. U. H., Khalid, M., Lavie, C. J., Ventura, H., Mukherjee, D., et al. (2019). Diabetic Cardiomyopathy - A Comprehensive Updated Review. Prog. Cardiovasc. Dis. 62 (4), 315-326. doi:10.1016/j.pcad.2019.03.003 
Mustroph, J., Neef, S., and Maier, L. S. (2017). CaMKII as a Target for Arrhythmia Suppression. Pharmacol. Ther. 176, 22-31. doi:10.1016/ j.pharmthera.2016.10.006

Nassal, D., Gratz, D., and Hund, T. J. (2020). Challenges and Opportunities for Therapeutic Targeting of Calmodulin Kinase II in Heart. Front. Pharmacol. 11, 35. doi:10.3389/fphar.2020.00035

Ogurtsova, K., da Rocha Fernandes, J. D., Huang, Y., Linnenkamp, U., Guariguata, L., Cho, N. H., et al. (2017). IDF Diabetes Atlas: Global Estimates for the Prevalence of Diabetes for 2015 and 2040. Diabetes Res. Clin. Pract. 128, 40-50. doi:10.1016/j.diabres.2017.03.024

Onal, B., Gratz, D., and Hund, T. J. (2017). Ca2+/calmodulin-dependent Kinase IIdependent Regulation of Atrial Myocyte Late Na+ Current, $\mathrm{Ca} 2+$ Cycling, and Excitability: a Mathematical Modeling Study. Am. J. Physiology-Heart Circulatory Physiol. 313 (6), H1227-H1239. doi:10.1152/ajpheart.00185.2017

Pereira, L., Bare, D. J., Galice, S., Shannon, T. R., and Bers, D. M. (2017). $\beta$-Adrenergic Induced SR Ca 2+ Leak Is Mediated by an Epac-NOS Pathway. J. Mol. Cell Cardiol. 108, 8-16. doi:10.1016/j.yjmcc.2017.04.005

Pereira, L., Matthes, J., Schuster, I., Valdivia, H. H., Herzig, S., Richard, S., et al. (2006). Mechanisms of [Ca2+]i Transient Decrease in Cardiomyopathy of Db/ db Type 2 Diabetic Mice. Diabetes 55 (3), 608-615. doi:10.2337/ diabetes.55.03.06.db05-1284

Pham, T., Loiselle, D., Power, A., and Hickey, A. J. R. (2014). Mitochondrial Inefficiencies and Anoxic ATP Hydrolysis Capacities in Diabetic Rat Heart. Am. J. Physiology-Cell Physiol. 307 (6), C499-C507. doi:10.1152/ ajpcell.00006.2014

Popescu, I., Yin, G., Velmurugan, S., Erickson, J. R., Despa, F., and Despa, S. (2019). Lower Sarcoplasmic Reticulum Ca2+ Threshold for Triggering Afterdepolarizations in Diabetic Rat Hearts. Heart Rhythm 16 (5), 765-772. doi:10.1016/j.hrthm.2018.11.001

Prakoso, D., Lim, S. Y., Erickson, J. R., Wallace, R. S., Lees, J. G., Tate, M., et al. (2021). Fine-tuning the Cardiac O-GlcNAcylation Regulatory Enzymes Governs the Functional and Structural Phenotype of the Diabetic Heart. Cardiovasc. Res. doi:10.1093/cvr/cvab043

Purohit, A., Rokita, A. G., Guan, X., Chen, B., Koval, O. M., Voigt, N., et al. (2013). Oxidized CaMKII Triggers Atrial Fibrillation. Circulation (New York, NY) 128 (16). doi:10.1161/circulationaha.113.003313

Ramirez-Correa, G. A., Ma, J., Slawson, C., Zeidan, Q., Lugo-Fagundo, N. S., Xu, M., et al. (2015). Removal of Abnormal MyofilamentO-GlcNAcylation Restores Ca2+Sensitivity in Diabetic Cardiac Muscle. Diabetes 64 (10), 3573-3587. doi:10.2337/db14-1107

Ravens, U., and Cerbai, E. (2008). Role of Potassium Currents in Cardiac Arrhythmias. Europace 10 (10), 1133-1137. doi:10.1093/europace/eun193

Rehman, K., and Akash, M. S. H. (2017). Mechanism of Generation of Oxidative Stress and Pathophysiology of Type 2 Diabetes Mellitus: How Are They Interlinked? J. Cell. Biochem. 118 (11), 3577-3585. doi:10.1002/jcb.26097

Ren, J., and Bode, A. M. (2000). Altered Cardiac Excitation-Contraction Coupling in Ventricular Myocytes from Spontaneously Diabetic BB Rats. Am. J. Physiology-Heart Circulatory Physiol. 279 (1), H238-H244. doi:10.1152/ ajpheart.2000.279.1.h238

Rolim, N., Skårdal, K., Høydal, M., Sousa, M. M., Malmo, V., Kaurstad, G., et al. (2015). Aerobic Interval Training Reduces Inducible Ventricular Arrhythmias in Diabetic Mice after Myocardial Infarction. Basic Res. Cardiol. 110 (4), 44. doi:10.1007/s00395-015-0502-9

Rosenberg, O. S., Deindl, S., Sung, R.-J., Nairn, A. C., and Kuriyan, J. (2005). Structure of the Autoinhibited Kinase Domain of CaMKII and SAXS Analysis of the Holoenzyme. Cell 123 (5), 849-860. doi:10.1016/j.cell.2005.10.029

Salem, K. A., Qureshi, M. A., Sydorenko, V., Parekh, K., Jayaprakash, P., Iqbal, T., et al. (2013). Effects of Exercise Training on Excitation-Contraction Coupling and Related mRNA Expression in Hearts of Goto-Kakizaki Type 2 Diabetic Rats. Mol. Cell Biochem 380 (1-2), 83-96. doi:10.1007/s11010-013-1662-2

Silberman, G. A., Fan, T.-H. M., Liu, H., Jiao, Z., Xiao, H. D., Lovelock, J. D., et al. (2010). Uncoupled Cardiac Nitric Oxide Synthase Mediates Diastolic Dysfunction. Circulation 121 (4), 519-528. doi:10.1161/ circulationaha.109.883777

Soliman, H., Nyamandi, V., Garcia-Patino, M., Zhang, P.-C., Lin, E., Jia, Z. P., et al. (2019). ROCK2 Promotes Ryanodine Receptor Phosphorylation and Arrhythmic Calcium Release in Diabetic Cardiomyocytes. Int. J. Cardiol. 281, 90-98. doi:10.1016/j.ijcard.2019.01.075
Sommese, L., Valverde, C. A., Blanco, P., Castro, M. C., Rueda, O. V., Kaetzel, M., et al. (2016). Ryanodine Receptor Phosphorylation by CaMKII Promotes Spontaneous $\mathrm{Ca} 2+$ Release Events in a Rodent Model of Early Stage Diabetes: The Arrhythmogenic Substrate. Int. J. Cardiol. 202, 394-406. doi:10.1016/j.ijcard.2015.09.022

Song, Y.-H., Cho, H., Ryu, S.-Y., Yoon, J.-Y., Park, S.-H., Noh, C.-I., et al. (2010). L-type Ca2+ Channel Facilitation Mediated by H2O2-Induced Activation of CaMKII in Rat Ventricular Myocytes. J. Mol. Cell Cardiol. 48 (4), 773-780. doi:10.1016/j.yjmcc.2009.10.020

Stølen, T. O., Høydal, M. A., Kemi, O. J., Catalucci, D., Ceci, M., Aasum, E., et al. (2009). Interval Training Normalizes Cardiomyocyte Function, Diastolic Ca2+ Control, and SR Ca2+ Release Synchronicity in a Mouse Model of Diabetic Cardiomyopathy. Circ. Res. 105 (6), 527-536. doi:10.1161/ CIRCRESAHA.109.199810

Swaminathan, P. D., Purohit, A., Soni, S., Voigt, N., Singh, M. V., Glukhov, A. V., et al. (2011). Oxidized CaMKII Causes Cardiac Sinus Node Dysfunction in Mice. J. Clin. Invest. 121 (8), 3277-3288. doi:10.1172/jci57833

Tuncay, E., Zeydanli, E. N., and Turan, B. (2011). Cardioprotective Effect of Propranolol on Diabetes-Induced Altered Intracellular Ca2+ Signaling in Rat. J. Bioenerg. Biomembr 43 (6), 747-756. doi:10.1007/s10863-011-9400-5

Umapathi, P., Mesubi, O. O., Banerjee, P. S., Abrol, N., Wang, Q., Luczak, E. D., et al. (2021). Excessive O -GlcNAcylation Causes Heart Failure and Sudden Death. Circulation 143 (17), 1687-1703. doi:10.1161/circulationaha.120.051911

Varga, Z. V., Giricz, Z., Liaudet, L., Haskó, G., Ferdinandy, P., and Pacher, P. (2015). Interplay of Oxidative, Nitrosative/nitrative Stress, Inflammation, Cell Death and Autophagy in Diabetic Cardiomyopathy. Biochim. Biophys. Acta (Bba) - Mol. Basis Dis. 1852 (2), 232-242. doi:10.1016/j.bbadis.2014.06.030

Vinogradova, T. M., Zhou, Y.-Y., Bogdanov, K. Y., Yang, D., Kuschel, M., Cheng, H., et al. (2000). Sinoatrial Node Pacemaker Activity Requires Ca 2+/ Calmodulin-dependent Protein Kinase II Activation. Circ. Res. 87 (9), 760-767. doi:10.1161/01.res.87.9.760

Voigt, N., Li, N., Wang, Q., Wang, W., Trafford, A. W., Abu-Taha, I., et al. (2012). Enhanced Sarcoplasmic Reticulum Ca 2+ Leak and Increased $\mathrm{Na}+-\mathrm{Ca} 2+$ Exchanger Function Underlie Delayed Afterdepolarizations in Patients with Chronic Atrial Fibrillation. Circulation 125 (17), 2059-2070. doi:10.1161/ circulationaha.111.067306

Wagner, S., Ruff, H. M., Weber, S. L., Bellmann, S., Sowa, T., Schulte, T., et al. (2011). Reactive Oxygen Species-Activated Ca/Calmodulin Kinase II $\delta$ Is Required for Late I Na Augmentation Leading to Cellular $\mathrm{Na}$ and $\mathrm{Ca}$ Overload. Circ. Res. 108 (5), 555-565. doi:10.1161/circresaha.110.221911

Wang, Q., Quick, A. P., Cao, S., Reynolds, J., Chiang, D. Y., Beavers, D., et al. (2018). Oxidized CaMKII (Ca(2+)/Calmodulin-dependent Protein Kinase II) Is Essential for Ventricular Arrhythmia in a Mouse Model of Duchenne Muscular Dystrophy. Circ. Arrhythm Electrophysiol. 11 (4), e005682. doi:10.1161/ circep.117.005682

Wehrens, X. H. T., Lehnart, S. E., Reiken, S. R., and Marks, A. R. (2004). Ca2+/ calmodulin-dependent Protein Kinase II Phosphorylation Regulates the Cardiac Ryanodine Receptor. Circ. Res. 94 (6), e61-70. doi:10.1161/ 01.res.0000125626.33738.e2

Wehrens, X., and Marks, A. R. (2003). Altered Function and Regulation of Cardiac Ryanodine Receptors in Cardiac Disease. Trends Biochem. Sci. 28 (12), 671-678. doi:10.1016/j.tibs.2003.10.003

Wu, Y., Gao, Z., Chen, B., Koval, O. M., Singh, M. V., Guan, X., et al. (2009). Calmodulin Kinase II Is Required for Fight or Flight Sinoatrial Node Physiology. Proc. Natl. Acad. Sci. 106 (14), 5972-5977. doi:10.1073/ pnas. 0806422106

Wu, Y., MacMillan, L. B., McNeill, R. B., Colbran, R. J., and Anderson, M. E. (1999). CaM Kinase Augments Cardiac L-type Ca2+ Current: a Cellular Mechanism for Long Q-T Arrhythmias. Am. J. Physiology-Heart Circulatory Physiol. 276 (6), H2168-H2178. doi:10.1152/ajpheart.1999.276.6.h2168

Wu, Y., Roden, D. M., and Anderson, M. E. (1999). Calmodulin Kinase Inhibition Prevents Development of the Arrhythmogenic Transient Inward Current. Circ. Res. 84 (8), 906-912. doi:10.1161/01.res.84.8.906

Yang, Y., He, J., Yuan, M., Tse, G., Zhang, K., Ma, Z., et al. (2020). Xanthine Oxidase Inhibitor Allopurinol Improves Atrial Electrical Remodeling in Diabetic Rats by Inhibiting CaMKII/NCX Signaling. Life Sci. 259, 118290. doi:10.1016/j.lfs.2020.118290

Yu, P., Hu, L., Xie, J., Chen, S., Huang, L., Xu, Z., et al. (2018). O-GlcNAcylation of Cardiac Nav1.5 Contributes to the Development of 
Arrhythmias in Diabetic Hearts. Int. J. Cardiol. 260, 74-81. doi:10.1016/ j.ijcard.2018.02.099

Zethelius, B., Gudbjörnsdottir, S., Eliasson, B., Eeg-Olofsson, K., and Cederholm, J. (2014). Level of Physical Activity Associated with Risk of Cardiovascular Diseases and Mortality in Patients with Type-2 Diabetes: Report from the Swedish National Diabetes Register. Eur. J. Prev. Cardiolog 21 (2), 244-251. doi:10.1177/2047487313510893

Zhang, M., and Shah, A. M. (2014). ROS Signalling between Endothelial Cells and Cardiac Cells. Cardiovasc. Res. 102 (2), 249-257. doi:10.1093/cvr/cvu050

Zhao, Z., Fefelova, N., Shanmugam, M., Bishara, P., Babu, G. J., and Xie, L.-H. (2011). Angiotensin II Induces Afterdepolarizations via Reactive Oxygen Species and Calmodulin Kinase II Signaling. J. Mol. Cell Cardiol. 50 (1), 128-136. doi:10.1016/j.yjmcc.2010.11.001

Zhu, W.-Z., Wang, S.-Q., Chakir, K., Yang, D., Zhang, T., Brown, J. H., et al. (2003). Linkage of $\beta 1$-adrenergic Stimulation to Apoptotic Heart Cell Death through Protein Kinase A-independent Activation of $\mathrm{Ca} 2+/$ calmodulin Kinase II. J. Clin. Invest. 111 (5), 617-625. doi:10.1172/jci200316326
Conflict of Interest: The authors declare that the research was conducted in the absence of any commercial or financial relationships that could be construed as a potential conflict of interest.

Publisher's Note: All claims expressed in this article are solely those of the authors and do not necessarily represent those of their affiliated organizations, or those of the publisher, the editors and the reviewers. Any product that may be evaluated in this article, or claim that may be made by its manufacturer, is not guaranteed or endorsed by the publisher.

Copyright (๑) 2021 Veitch, Power and Erickson. This is an open-access article distributed under the terms of the Creative Commons Attribution License (CC $B Y$ ). The use, distribution or reproduction in other forums is permitted, provided the original author(s) and the copyright owner(s) are credited and that the original publication in this journal is cited, in accordance with accepted academic practice. No use, distribution or reproduction is permitted which does not comply with these terms. 